\title{
Análise de parâmetros de humanização para espaços públicos
}

\author{
Analysis of humanization parameters for public spaces
}

\author{
Maikieli Bussolaro*, Gislaine da Silva Fernandes**, Adriana Kunen***, Mônica \\ Aparecida Gonçalves Scatola****
}

*Arquiteta e Urbanista graduada pela Universidade Paranaense (UNIPAR), Campus Francisco Beltrão, Paraná ORCID: $\quad$ 0000-0002-59353818

${ }^{\star * \star}$ Arquiteta e Urbanista graduada pela Universidade Tuiuti do Paraná. Mestre em Engenharia Civil pela Universidade Tecnológica Federal do Paraná (UTFPR). Professora do Departamento de Arquitetura e Urbanismo da Universidade Paranaense, Campus Francisco Beltrão, Paraná.

ORCID: $\quad$ 0000-0003-3312 2461

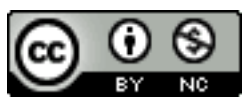

Recebido: 20/02/2020

Aceito: $22 / 06 / 2020$

https://doi.org/10.37916/arq.urb.v28i.413

usjt • arq.urb • número 28 | maio-agosto de 2020

${ }^{* *}$ Arquiteta e Urbanista graduada pela Universidade Federa de Viçosa (UFV). Mestre em Engenharia Civil pelo Programa Engenharia da Construção (UFV). Professora e coordenadora do Departamento de Arquitetura e Urbanismo da Universidade Paranaense Campus Francisco Beltrão, Paraná

ORCID: $\quad 0000-0002-6564$ $518 \mathrm{X}$

${ }^{\star * * \star}$ Arquiteta e Urbanista graduada pela Universidade $\mathrm{Pa}$ ranaense (UNIPAR), Campus Cascavel, Paraná. Mestre em Desenvolvimento Urbano Regional pela Universidade Tecnológica Federal do Paraná (UTFPR). Professora do Departamento de Arquitetura e Urbanismo da Universidade Paranaense, Campus Francisco Beltrão, Paraná

ORCID: $\quad$ 0000-0002-03471145

$$
\text { ção. }
$$

\section{Resumo}

Com cada vez mais pessoas vivendo no perímetro urbano, a cidade de Coronel Vivida, Paraná, possui um centro público e administrativo que não atende à demanda devido às más condições de uso e dimensionamentos dos espaços. Portanto, este trabalho tem como objetivo identificar e avaliar parâmetros de humanização para espaços públicos e administrativos, abordando como estudo de caso a Praça, a Prefeitura e a Câmara Municipal da cidade. Para isso, é realizada uma revisão bibliográfica, identificando os parâmetros e organizando-os em cinco grupos de atributos: elementos naturais, estrutura, acessibilidade, identidade e legibilidade. Posteriormente, os parâmetros são avaliados por meio da aplicação de uma avaliação pós-ocupação, do ponto de vista técnico e dos usuários. Como resultado observou-se que grande parte dos usuários se sente insatisfeita com os espaços e percebem a necessidade de um novo projeto arquitetônico, urbanístico e paisagístico, que valorize a importância do centro urbano administrativo integrado à comunidade. As contribuições visam à importância da comunicação pública e política, por meio da relação ambiente/comportamento, como forma de inclusão e representatividade social.

Palavras-chave: Análise da forma arquitetônica. Projeto de espaço público. Avaliação pós-ocupação.

\section{Abstract}

In the municipality of Coronel Vivida, Paraná State Brazil, the urban population grows every year. In this condition, the public, and administrative center does not meet the demand due to poor conditions of use, and sizing of spaces. In this context, this work aims to identify, and evaluate humanization parameters for public and administrative spaces, approaching as a case study the Square, the City Hall, and the Town Hall. For this, a literature review was performed, identifying the parameters, and organizing them into five groups of attributes: natural elements, structure, accessibility, identity, and readability. These parameters are evaluated by applying a post-occupancy assessment from the technical, and user point of view. The results showed that most users are dissatisfied with the spaces, and realize the need for a new architectural, urban, and landscape project that values the importance of the administrative urban center integrated with the community. The contributions are intended to enable public, and political communication, through the relationship environment / behavior, as a form of inclusion, and social representation.

Keywords: Architectural form analysis. Public space design. Post-occupation evaluation. 


\section{Introdução}

A preocupação com a otimização dos espaços públicos e administrativos no Brasil começa a surgir por volta dos anos 1950 e 1970, quando ocorreu um momento de descentralização das cidades devido às constantes transformações sociais, ambientais, políticas e econômicas, no período que sucedeu a Segunda Guerra Mundial. O objetivo da época era renovar os centros urbanos, através dos centros cívicos, devolvendo o espírito de "coração da cidade", criando locais de representatividade social e administrativa, destinados à efetivação das condições de cidadania (ALMEIDA, 2001; CALDEIRA, 2007; PEREIRA, 2012).

A função social desses centros deveria considerar a estrutura e monumentalidade dos edifícios. $\mathrm{O}$ interior deveria possuir elementos naturais, como árvores, plantas, água, sol e sombra, de forma harmônica com o projeto arquitetônico, pois a paisagem tem um papel importante para agradar o homem a partir de um ponto de vista social, estético, técnico e psicológico (PEREIRA, 2012). Com isso, o conceito de espaço público, interno ou externo, se volta ao resgate da qualidade de vida urbana e da identidade local. Passa a ser qualificado por meio da legibilidade, da escala do usuário, da abrangência de seu campo visual e da diversidade de usos (JACOBS, 2007; LYNCH, 2011; GEHL, 2013; GOETTEMS; BUENO, 2018).

Segundo Hertzberger (2015, p. 253), "[...] todos tendem a considerar opressivos os edifícios de escala excessivamente grande, que diminuem os seres humanos [...]", pois são vistos como regimes totalitários, que buscam através da arquitetura causar temor por meio das dimensões. Porém, não apenas as dimensões do edifício podem se tornar opressivas e hostis ao cidadão, como também a falta de acesso universal.

No que diz respeito às praças, sabe-se que nesses espaços cívicos podem ser levantados alguns conceitos, segundo diferentes autores. Para Oliveira e Mascaró (2007, p. 61), “[...] a praça é um espaço aberto público cercado de ruas por todos os lados, 
concebido como espaço intencional de encontros sociais e atividades de lazer". Para Lynch (2011), as praças são uma espécie de escape à vida urbana, com a finalidade de garantir o bem-estar das pessoas. Lamas (1993) conceitua a praça como espaço público urbano, de uso coletivo, que intencionalmente foi organizado a nível espacial e de desenho, no centro da cidade, para que nele ocorressem encontros. Para Mascaró (2008), as praças possuem ambiência própria, singular, com alto valor simbólico, que sustentam a história e a tradição de uma cidade.

Ao se pensar a praça como espaço público é necessário que seus atributos possam garantir a urbanidade ao local, aproximando diferentes grupos sociais. Entretanto, devido à privatização dos espaços de uso coletivo, esses espaços vêm perdendo a sua representatividade social (ECKER; VAZ, 2015). No urbanismo moderno, o espaço construído ganhou maior importância em relação ao espaço livre, devido ao desenvolvimento acelerado das cidades e às novas tecnologias. $O$ espaço público passou a ser calculado, e toda sobra irregular em meio às construções ou ruas passou a ser designada praça. Desta forma, com o passar do tempo, a praça passou a perder a intensidade da vida pública (SITTE, 1992).Deste modo, existe atualmente uma carência por espaços que representem a real identidade do povo, do exercício da cidadania, do lazer e da interação social. Com o aumento da densidade demográfica das cidades, a demanda por espaços públicos é maior, porém, os responsáveis por essa reformulação têm em vista objetivar seus próprios interesses (OLIVEIRA; MASCARÓ, 2007). Esses espaços vêm se tornando lugares subutilizados e que não atendem mais às condições de proporcionar vida pública (BENEDET; BENEDET; SILVA, 2015). Muitas vezes, os espaços e edifícios públicos são favoráveis para que isso aconteça. Eles não atendem mais à demanda de usuários, são barreiras ou obras monumentais, as quais repelem o cidadão comum, e esta hostilidade na arquitetura interfere diretamente nos atos humanos. Existe a necessidade de tornar os espaços públicos mais convidativos, para que possam contribuir para a percepção do espaço, com equivalência e equilíbrio de uso sem distinção, fazendo com que as pessoas se sintam melhor nesses espaços. "O bom lugar é aquele no qual todos querem ficar e se sentem atraídos para ali estar [...]" (NÓBREGA; TRINDADE, 2019, p. 66).

Essa situação se visualiza no caso dos edifícios da Prefeitura, Câmara e da Praça Municipal da cidade de Coronel Vivida, Paraná, construídos no início dos anos 60 , e que devido às ações do tempo e ao dimensionamento dos espaços, estão em más condições de uso, não atraem as pessoas e não comportam as necessidades atuais. 
A cidade de Coronel Vivida, segundo o último censo realizado em 2010 pelo Instituto Brasileiro de Geografia e Estatística (IBGE), possui 15.445 habitantes, e apenas 6.304 deles vivem no meio rural. Isso comprova que existem mais pessoas vivendo no perímetro urbano, por consequência, deve-se ter espaços públicos de qualidade, que supram as demandas sociais, ambientais, culturais e econômicas.

Portanto, o objetivo deste trabalho é identificar e avaliar parâmetros de humanização para espaços públicos e administrativos, abordando como estudo de caso a Praça, a Prefeitura e a Câmara Municipal da cidade de Coronel Vivida, Paraná, como fundamento para a criação de uma identidade vividense, da prática da cidadania, do lazer e da interação social. Desta forma, contribuir no processo de projeto ao se pensar no usuário e em como o projeto pode atuar nas suas ações e comportamento.

A metodologia da pesquisa é organizada em duas etapas. A primeira etapa comporta a revisão bibliográfica, com análise e interpretação de diferentes fontes, a partir do estudo de artigos, livros, dissertação e tese, nas quais foram identificados os parâmetros de humanização aplicáveis em espaços públicos. Dentre os autores que teorizam sobre os atributos dos espaços públicos urbanos, optou-se por Alexander et al., (2013), Lynch (2011) e Ber- nardi et al., (in: KOWALTOWSKI et al., 2011, p. 222-244), que tratam da qualidade espacial através de um planejamento de espaços públicos ligados a valores e padrões de comportamento.

A seleção dos parâmetros foi realizada por meio de alguns já estabelecidos pelos autores, como é o caso de Alexander et al., (2013) e Lynch (2011); outros interpretados pela autora, provenientes da obra de Bernardi et al., (in: KOWALTOWSKI et al., 2011, p. 222-244), com base em diretrizes do processo de projeto em arquitetura para alcançar a acessibilidade universal; e, ainda, alguns acrescentados pela autora, com base em leituras complementares e conhecimento do lugar objeto de estudo e suas necessidades. Após esta seleção, foi formulada uma tabela na qual os parâmetros foram agrupados por características e objetivos comuns, totalizando cinco grupos de atributos: elementos naturais, estrutura, acessibilidade, identidade e legibilidade. Os parâmetros identificados com a letra " $A$ " correspondem à seleção dos parâmetros projetuais de Alexander et al. (2013); os identificados com a letra "B" são abordados por Lynch (2011); com a letra "C" de Bernardi et al., (in: KOWALTOWSKI et al., 2011, p. 222-244); e com a letra " $D$ " os parâmetros elaborados pela autora.

Após essa identificação foi realizada a segunda etapa desse trabalho: uma avaliação pós-ocupação (APO), do ponto de vista técnico e do ponto de vista 
dos usuários da Praça, da Câmara e da Prefeitura Municipal. Para tanto se utilizou o método walkthrough, que constitui uma análise que combina observação com entrevista, conforme Rheingantz et al., (2009). Foram definidos como usuários desses espaços os funcionários e a comunidade em geral. Em seguida foram elaboradas as entrevistas e o roteiro do walkthrough, de modo que abordassem os principais parâmetros de humanização identificados. As 20 entrevistas coletadas aconteceram nos dias 14 e 15 de abril do ano de 2019, no período da manhã e no período da tarde.

Das perguntas ao usuário relativas a Câmara e a Prefeitura Municipal: Na sua opinião, este espaço é confortável? / Na sua opinião, este espaço é de fácil acesso? / Na sua opinião, o espaço tem fácil legibilidade (orientação)? / Qual o seu meio de transporte? / Na sua opinião, a arquitetura desse espaço é convidativa? / Na sua opinião, este espaço é pequeno para atividade que exerce? / Na sua opinião, existe acessibilidade as pessoas com dificuldades de locomoção $(\mathrm{PcD})$ ? / Na sua opinião, o edifício é aberto ao público em geral? / Na sua opinião, existe poluição sonora (algum barulho perturbador)? Se sim, qual? / Na sua opinião, como estão as condições de uso de espaço? / Na sua opinião, como estão as condições de ventilação desse espaço? / Na sua opinião, como estão as condições de iluminação desse espaço? / Na sua opinião, como estão as condições de insolação natural desse espaço? / Na sua opinião, como estão as condições de arborização (presença do verde) do espaço? / Com qual frequência você vai as sessões da Câmara Municipal? / Quais são suas sugestões para melhorar esse espaço?

Das perguntas ao usuário relativas a Praça Municipal: Na sua opinião, este espaço é confortável? / $\mathrm{Na}$ sua opinião, este espaço é de fácil acesso? / $\mathrm{Na}$ sua opinião, o espaço tem fácil legibilidade (orientação)? / Na sua opinião, existe poluição sonora (algum barulho perturbador)? Se sim, qual? / Na sua opinião, como estão as condições de uso de espaço? / Com qual frequência utiliza a praça? / Em qual período do dia costuma usar a praça? / Qual o seu meio de transporte? / Atribua uma nota de 1 a 4 , sendo 1 a pior nota e 4 a melhor, quanto aos aspectos a seguir: Arborização (árvores); lluminação; Mobiliário (bancos e lixeiras); Pavimentação; Paisagismo (jardinagem); Acessibilidade à pessoa com dificuldades de locomoção (PcD); Manutenção e meIhorias; Playground (parquinho); Estacionamento; Diversidade de usos / Quais são suas sugestões para melhorar esse espaço?

Os dados levantados foram organizados a partir de tabela e gráficos, e em paralelo apresentou-se o ponto de vista técnico e do usuário. A partir disso, teceramse as discussões provenientes do levantamento e da identificação de parâmetros de humanização para espaços públicos, realizada inicialmente. 
Identificação dos parâmetros de humanização para espaços públicos

Uma das maiores dificuldades das cidades atuais é atingir um planejamento que vise aos interesses comuns da sociedade. A produção contínua e acelerada, baseada nos interesses das classes individuais e nos mais diversos agentes - políticos, entidades públicas e privadas e sociedade civil - estabelecem diferentes graus de influência, e isso reflete diretamente na caracterização dos espaços públicos. Além disso, com o aumento da densidade demográfica das cidades, a demanda por esses espaços aumenta. Nesse contexto, quando se busca a integração e a otimização desses espaços na malha urbana, apresenta-se um desafio aos planejadores urbanos (OLIVEIRA; MASCARÓ, 2007).

A função social do espaço público no Brasil tem enorme importância devido ao contexto histórico e político. Ele pode ser usado tanto para socializar como para segregar. São locais da construção da cidadania, de encontro político e religioso, definidores da forma urbana, abertos e acessíveis a todas as pessoas, espaços de coesão social, enquanto palco para expressão da democracia (ROGERS, 2001; MASCARÓ, 2007; BRANDÃO, 2008; ALEX, 2011; OLIVEIRA; GRAVE et al., 2011; GEHL, 2013). A falta de interesse público pelo planejamento urbano e infraestrutura desses espaços reflete no contraste de renda, na diversidade de clas- ses, na exclusão social, e resulta em uma cidade com relações sociais frágeis (OLIVEIRA; MASCARÓ, 2007; SANTIAGO; MARCHESANO, 2016).

Mesmo sabendo dessa realidade, uma das alternativas para se reverter essa problemática seria por meio do projeto. A arquitetura, o urbanismo e o paisagismo podem e devem devolver às cidades, o contato direto e a vida cívica, num espaço democrático. A sociedade pode estar integrada aos acontecimentos que ocorrem dentro dos edifícios públicos, numa relação afetuosa de respeito pelo que é de todos e, portanto, "[...] devem ser espaços projetados através da compreensão da dinâmica urbana a fim de refletirem as necessidades e anseios dos usuários [...]" (RAMOS; RAMOS; LYRA, 2019, p. 129).

O espaço democrático é de uso comum do povo em determinado momento e pode constituir um espaço da esfera pública política. Desse modo, "[...] na medida em que se potencializa a vida em público, apresentam-se com maior clareza os conflitos e possibilita-se o estabelecimento da razão comunicativa (HABERMAS, 1989) enquanto razão pública (ROCHLITZ, 2002), portanto, política" (QUEIROGA, 2011, p. 30).

Em muitos regimes totalitários ou democráticos a arquitetura é usada para inspirar temor, por meio das suas dimensões. Porém, da mesma forma que pode causar opressão, ela também pode criar condições especiais para que o autoritarismo não flo- 
resça (HERTZBERGER, 2015).

Alguns autores estudam essas condições e parâmetros voltados à necessidade de inclusão social desses espaços. Segundo Alexander et al., (2013) é por meio das necessidades humanas que se estabelece uma conexão entre parâmetros projetuais, como princípios da humanização dos espaços. Para que uma arquitetura atenda a esses princípios, faz-se indispensável a aplicação da escala humana, para estabelecer proporção, concepção das edificações, na valorização do verde, no conforto, na ordem e na variedade espacial, entre outras atribuições. Inclui entender o senso de lugar e o senso de habitar, pois a humanização é o equilíbrio entre o senso de urbanidade (lugar) e o senso de habitabilidade (habitar) (BARROS, 2008).

A obra de Alexander et al., (2013) é composta pela seleção de 253 parâmetros projetuais. A organização parte de que para cada problema de projeto há um conjunto de soluções, por meio de combinações. Para esse trabalho, por meio dos estudos de Barros (2008), Alexander et al., (2013) e também de Ecker e Vaz (2015), foram identificados parâmetros que se aplicam no contexto de ambientes públicos (prefeituras, câmara municipais e praças). Todos esses parâmetros podem tornar esses espaços e edificações mais humanizados. Aderindose a esses princípios procura-se influenciar na relação ambiente/comportamento, consequentemen- te, o lugar com a comunidade. Essa conexão, essa integração, faz do meio um espaço mais sustentável.

Lynch (2011) aborda algumas qualidades visuais específicas da cidade, que compõem a imagem mental que seus habitantes fazem dela e descreve atributos que estruturam a forma urbana e podem ser mapeados e captados pelos sentidos humanos. Para Bernardi et al., (in: KOWALTOWSKI et al., 2011, p. 222-244) o processo de projeto em arquitetura acontece a partir da necessidade contemporânea, da democratização do espaço e do uso da cidade, com base no direito do indivíduo de usufruir da convivência social e urbana. Analisa-se, nesse caso, o quanto isso pode ajudar na busca pela integração desses espaços.

A acessibilidade é um atributo de sociabilidade urbana, pois a "receptividade" facilita o deslocamento, pode ser entendida por meio da distância, da qualidade do espaço para atividades e da existência de barreiras físicas (LYNCH, 2011). Para Bernardi et al., p. 227 (in: KOWALTOWSKI et al., 2011, p. 222244) o conceito de acessibilidade se expande, pois, inclui "[...] o acesso à percepção e à vivência da qualidade arquitetônica do ambiente construído [...]", ou seja, considera as habilidades de interação de cada indivíduo. Proporcionar isso é garantir a cidadania e aceitar a diversidade (BERNARDI et al., in: KOWALTOWSKI et al., 2011, p. 222-244). A identi- 


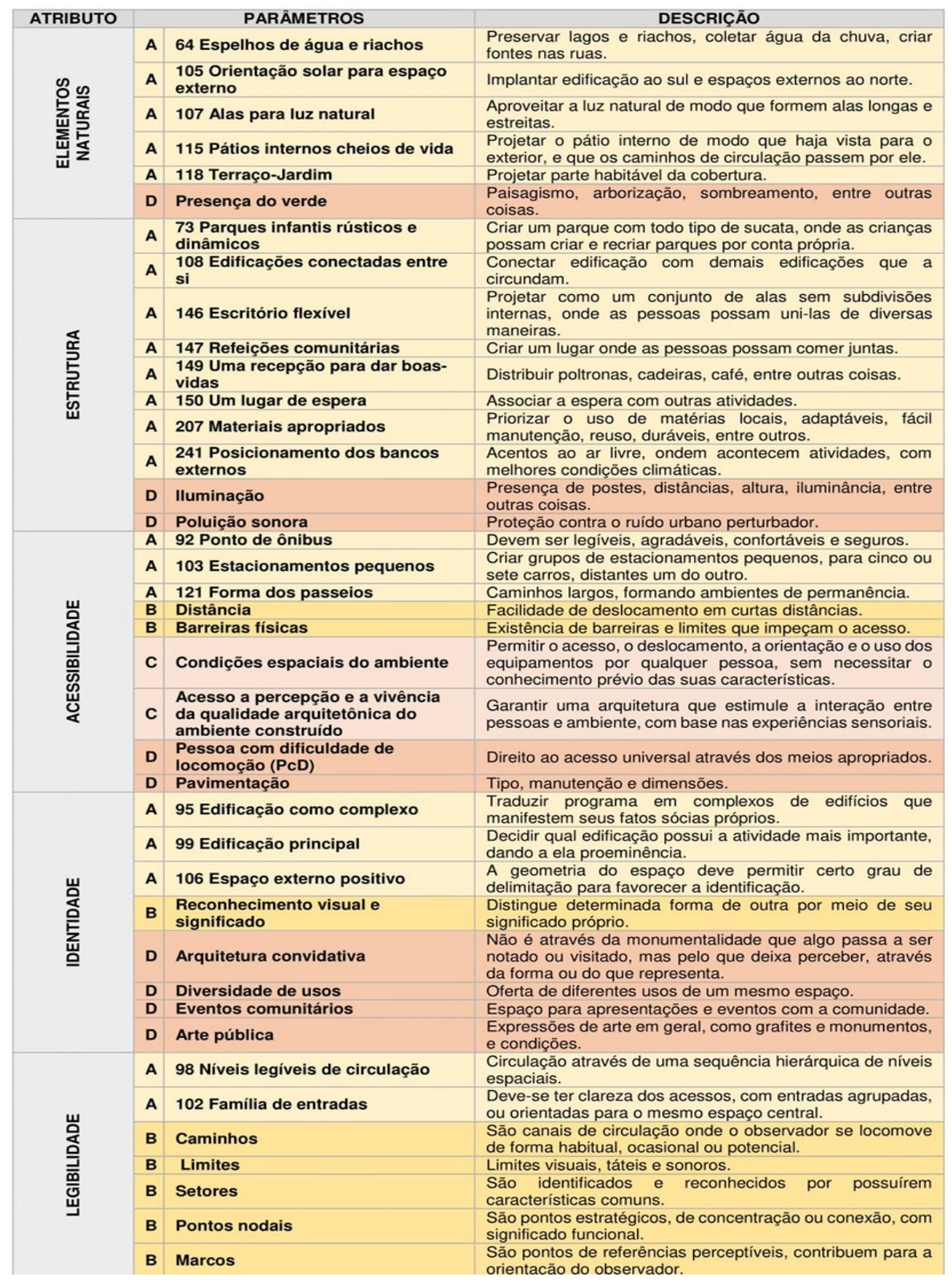

Figura 1. Parâmetros de análise aplicados à avaliação pós-ocupação (APO). Fonte: Acervo da(s) Autor(as).

usjt • arq.urb • número 28 | maio-agosto de 2020 dade distingue determinada forma de outra pelo reconhecimento visual e pelo significado, conduzindo o indivíduo ao seu destino. A legibilidade garante aos espaços serem facilmente reconhecíveis e, ao mesmo tempo, ligados ao todo, criando um sistema hierárquico, que parte de uma sequência de eventos (LYNCH, 2011). É uma "[...] habilidade de aprender um caminho e refazê-lo mentalmente, ligada à organização e à comunicação do relacionamento dinâmico do homem com o espaço e com o ambiente [...]" (BERNARDI et al., p. 230, in: KOWALTOWSKI et al., 2011, p. 222-244).

Os parâmetros de humanização para espaços públicos selecionados serão descritos a seguir, de forma sintetizada, por meio da Figura 1.

\section{Aplicação da avaliação pós-ocupação (APO)}

Após a aplicação dos métodos selecionados, os dados foram tabulados e analisados. Os resultados da avaliação do ponto de vista técnico e do ponto de vista dos usuários da Prefeitura e da Câmara Municipal, assim como da Praça Municipal são apresentados nas Figuras 2, 3 e 4, que sintetizam uma avaliação geral em: "satisfatória", "neutra", "insatisfatória" e "inexistente". A seguir é realizada a discussão, de acordo com os parâmetros mais problemáticos e com a relação dentro do grupo de atributo a que pertence, de modo a deixar mais clara a compreensão dos espaços públicos avaliados. Os casos que os pontos de vista técnico e do usuário diferem são apresentados e a justificativa parte pela observação técnica. 


\begin{tabular}{|c|c|c|c|c|c|c|}
\hline \multirow[t]{2}{*}{ ATRIBUTO } & \multirow{2}{*}{\multicolumn{2}{|c|}{ PARÂMETROS }} & \multicolumn{4}{|c|}{$\begin{array}{l}\text { AVALIAÇÃO GERAL } \\
\text { Técnico }(X) \text { Usuário }(X)\end{array}$} \\
\hline & & & Satisfatória & Neutra & Insatisfatória & Inexistente \\
\hline \multirow{6}{*}{ 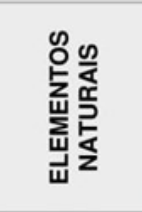 } & A & 64 Espelhos de água e riachos & & & XX & \\
\hline & A & $\begin{array}{l}105 \text { Orientação solar para espaço } \\
\text { externo }\end{array}$ & & $\mathrm{x}$ & $\mathbf{x}$ & \\
\hline & A & 107 Alas para luz natural & & & $X X$ & \\
\hline & A & 115 Pátios internos cheios de vida & & & & $\mathbf{X X}$ \\
\hline & A & 118 Terraço-Jardim & & & & $x X$ \\
\hline & D & Presença do verde & $\mathrm{x}$ & $\mathbf{x}$ & & \\
\hline \multirow{10}{*}{ 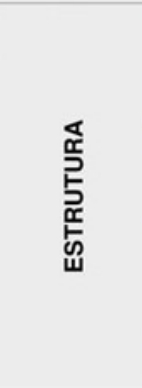 } & A & $\begin{array}{l}73 \text { Parques infantis rústicos e } \\
\text { dinâmicos }\end{array}$ & & & $x \mathbf{x}$ & \\
\hline & A & 108 Edificações conectadas entre si & & & & $\mathbf{X X}$ \\
\hline & A & 146 Escritório flexivel & & & & $\mathbf{X X}$ \\
\hline & A & 147 Refeições comunitárias & & & & $\mathbf{X X}$ \\
\hline & A & $\begin{array}{l}149 \text { Uma recepção para dar boas- } \\
\text { vidas }\end{array}$ & & & $x x$ & \\
\hline & A & 150 Um lugar de espera & & & $\mathrm{XX}$ & \\
\hline & A & 207 Materiais apropriados & $\mathbf{x}$ & $\mathbf{x}$ & & \\
\hline & A & $\begin{array}{l}241 \text { Posicionamento dos bancos } \\
\text { externos }\end{array}$ & & & $x x$ & \\
\hline & D & Iluminação & & & $\mathbf{X X}$ & \\
\hline & D & Poluição sonora & & & $x X$ & \\
\hline \multirow{9}{*}{ 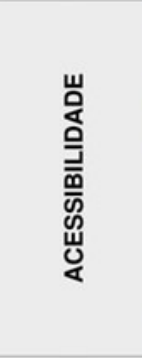 } & A & 92 Ponto de ônibus & $X X$ & & & \\
\hline & A & 103 Estacionamentos pequenos & $\mathbf{x}$ & & $\mathbf{x}$ & \\
\hline & A & 121 Forma dos passeios & & $\mathbf{x}$ & $\mathbf{x}$ & \\
\hline & B & Distância & $\mathrm{x}$ & & $\mathbf{x}$ & \\
\hline & B & Barreiras físicas & & $\mathbf{x}$ & $\mathbf{x}$ & \\
\hline & C & Condições espaciais do ambiente & & $\mathbf{x}$ & $\mathbf{x}$ & \\
\hline & C & $\begin{array}{l}\text { Acesso a percepção e a vivência da } \\
\text { qualidade arquitetônica do ambiente } \\
\text { construído }\end{array}$ & & & $\mathrm{xx}$ & \\
\hline & D & $\begin{array}{l}\text { Pessoa com dificuldade de } \\
\text { locomoção (PcD) }\end{array}$ & & & $x x$ & \\
\hline & D & Pavimentação & & & $x x$ & \\
\hline \multirow{8}{*}{ 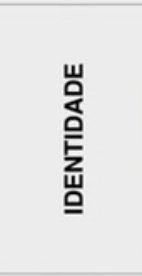 } & A & 95 Edificação como complexo & & & $\mathrm{XX}$ & \\
\hline & A & 99 Edificação principal & $\mathbf{x}$ & $\mathbf{x}$ & & \\
\hline & A & 106 Espaço externo positivo & & $x \mathrm{X}$ & & \\
\hline & B & $\begin{array}{l}\text { Reconhecimento visual e } \\
\text { significado }\end{array}$ & & & $x \mathrm{X}$ & \\
\hline & D & Arquitetura convidativa & & & $\mathbf{X X}$ & \\
\hline & D & Diversidade de usos & & & $\mathrm{XX}$ & \\
\hline & D & Eventos comunitários & & $\mathrm{XX}$ & & \\
\hline & D & Arte pública & & & & $\mathbf{X X}$ \\
\hline \multirow{7}{*}{ 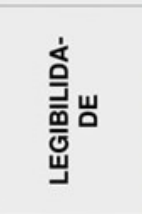 } & A & 98 Niveis legiveis de circulação & & $\mathbf{X X}$ & & \\
\hline & A & 102 Família de entradas & $X X$ & & & \\
\hline & B & Caminhos & & $\mathrm{XX}$ & & \\
\hline & B & Limites & $\mathrm{x}$ & & $\mathbf{x}$ & \\
\hline & B & Setores & $\mathrm{x}$ & & $\mathbf{x}$ & \\
\hline & B & Pontos nodais & & & & $\mathbf{X X}$ \\
\hline & B & Marcos & & & & $X X$ \\
\hline
\end{tabular}

Figura 2. Avaliação geral dos resultados da avaliação pós-ocupação (APO). Fonte: Acervo da(s) Autor(as).

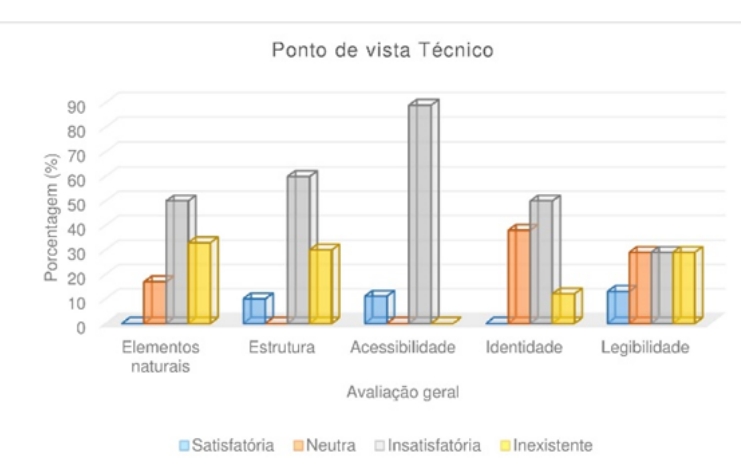

Figura 3. Gráfico síntese comparativo pelo ponto de vista Técnico. Fonte: Acervo da(s) Autor(as).

Ponto de vista do Usuário

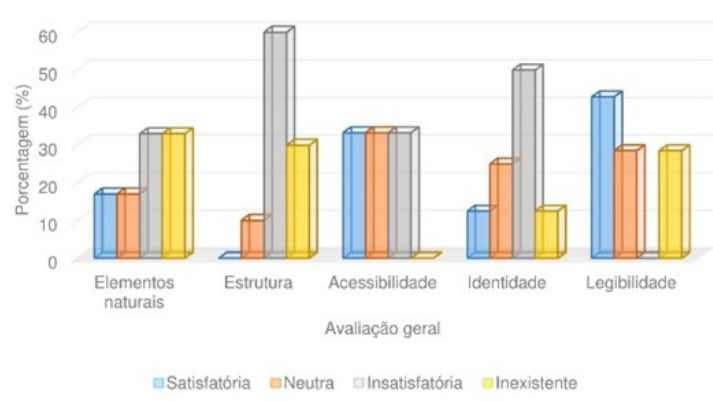

Figura 4. Gráfico síntese comparativo pelo ponto de vista do Usuário. Fonte: Acervo da(s) Autor(as). 


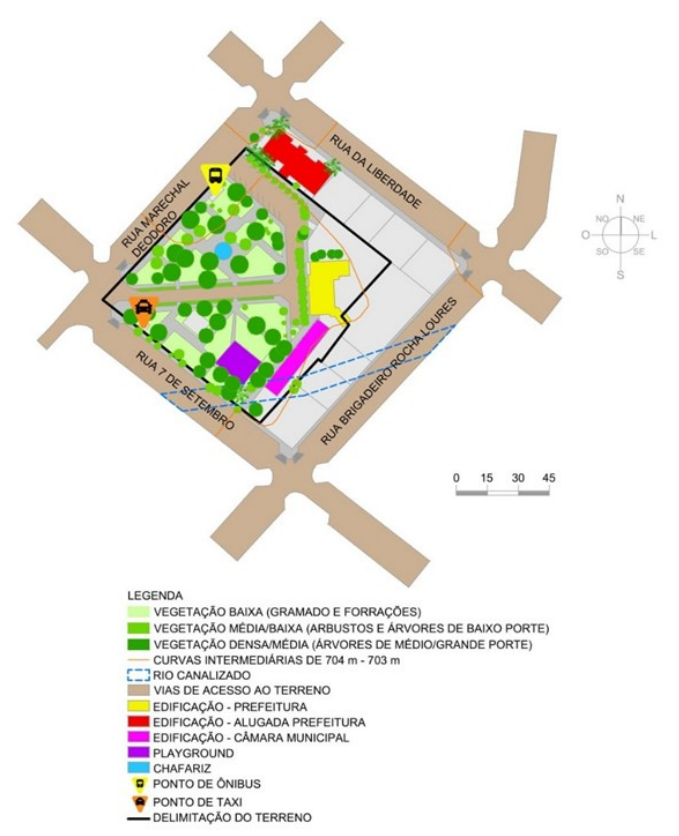

Figura 5. Mapa de implantação da Praça, Câmara Prefeitura Municipal de Coronel Vivida - PR. Fonte: Acervo da(s) Autor(as).
Ainda, para compreender melhor o objeto de estudo, foi elaborado um mapa de implantação da Praça, da Câmara e da Prefeitura Municipal de Coronel Vivida (Figura 5). Nele está representada a quadra que compreende o terreno, com as vias de acesso, os aspectos naturais, as edificações, os principais componentes da praça, além da indicação do ponto de ônibus e de taxi presentes nela.

\section{Elementos naturais}

Os elementos naturais, tanto pelo ponto visto dos usuários, quanto pelo ponto de vista técnico, apresentam uma avaliação geral "insatisfatória" ou "inexistente". Permanece uma necessidade por mais arborização, que ofereça um melhor sombreamento e espécies com mais cuidado e preservação, tendo em vista a presença de fungos e insetos invasores. Como sugestões dadas pelos usuários estão: a melhoria dos jardins e a adição de flores, como forma de colorir mais a praça; o funcionamento do chafariz, que atualmente passa a maior parte do tempo sem funcionar; e a criação de mais espaços com a presença do elemento água, a exemplo dos espelhos d'água.

Quanto aos edifícios, a orientação solar se avalia como "neutra", visto que as edificações estão mais ao norte, leste e sul do terreno, e a praça a oeste. Dessa forma, tem-se um aproveitamento dos ambientes internos nas questões de incidência solar direta, e a arborização da praça serve como barreira física de proteção. Porém, não existem alas para luz natural, pátios internos ou terraços-jardins que aproveitem as condições naturais do ambiente.

\section{Estrutura}

A estrutura apresenta parâmetros que envolvem a praça e as edificações administrativas. Pela percepção dos usuários e do ponto de vista técnico, a maioria dos parâmetros encontra-se "insatisfatório", com exceção dos parâmetros de escritório flexível e refeições comunitárias, que são "inexistentes". Apenas os materiais apropriados são avaliados como "satisfatórios", por serem encontrados na própria cidade, de fácil manutenção e duráveis.

A maioria dos entrevistados menciona existir poluição sonora no espaço devido à rota de caminhões na Rua da Liberdade, adjacente a um dos edifícios da prefeitura, aumentando os níveis de dificuldade de trabalho no local. Da mesma forma, as edificações não são conectadas entre si, o que dificulta a circulação entre elas. Além disso, as recepções e lugares de espera são pequenos e não ofertam outras atividades ao público que aguarda.

Quanto à iluminação, há poucos postes, o que causa insegurança ao usar a praça no período da noite e justifica o fato dos usuários entrevistados frequentarem a praça apenas durante o dia. 


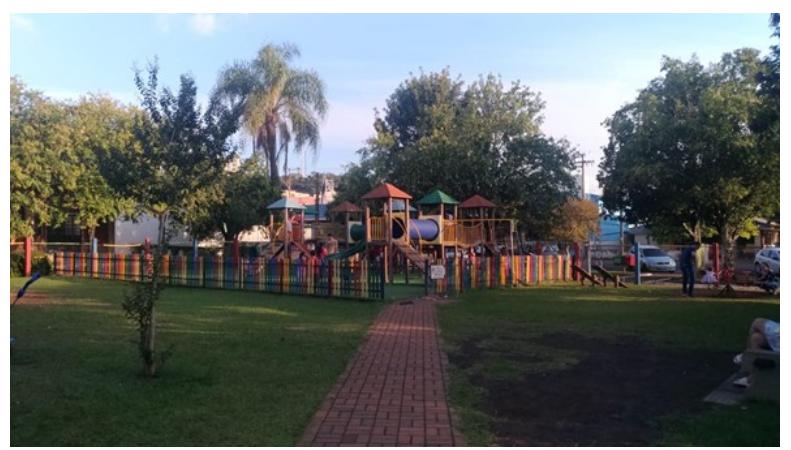

Figura 6. Playground da Praça Municipal de Coronel VividaPR. Fonte: Acervo da(s) Autor(as).

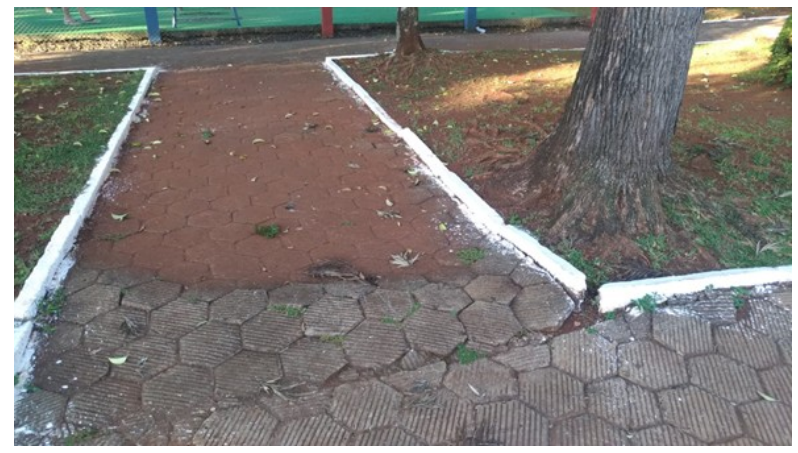

Figura 7. Tipologia dos passeios da Praça Municipal de Coronel Vivida- PR. Fonte: Acervo da(s) Autor(as)

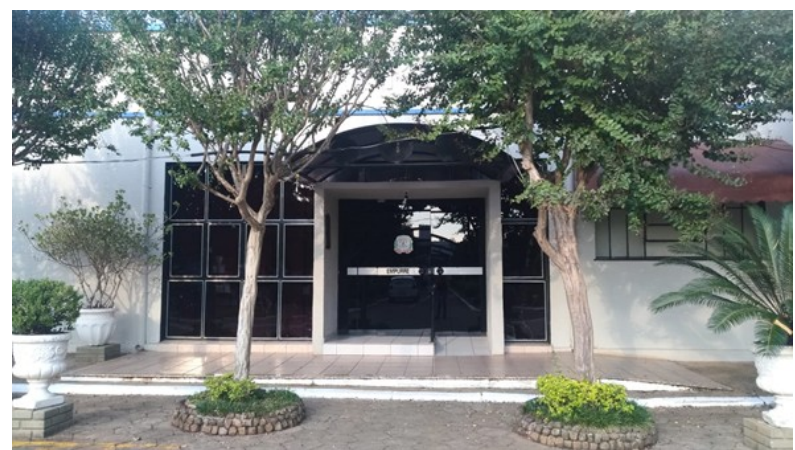

Figura 8. Acesso à edificação da Prefeitura Municipal de Coronel Vivida - PR. Fonte: Acervo da(s) Autor(as).

usjt • arq.urb • número 28 | maio-agosto de 2020
O posicionamento dos bancos externos foi avaliado como insatisfatório devido à insuficiência e às suas condições de manutenção. Segundo os usuários, existe a necessidade de mais bancos e lixeiras próximos ao playground, onde os pais costumam ficar aguardando seus filhos, além da implantação de banheiros e bebedouros, os quais também são inexistentes.

Quanto ao playground existente (Figura 6), parte dele não possui grama sintética, mas grama natural, o que resulta em terra, pó e barro em muitos locais. Os usuários sugerirão a criação de um campinho de futebol com grama sintética, próprio para as crianças jogarem. Além disso, solicitaram um espaço coberto para que possam usar a praça também em dias de chuva. Com a observação percebe-se que esse é o principal atrativo da praça até o momento. Sob o ponto de vista dos parques infantis rústicos e dinâmicos, ele não apresenta elementos que permitam à criança criar e recriar por conta própria, estimulando seus sentidos.

\section{Acessibilidade}

Conforme a avaliação geral, a maioria dos parâmetros de acessibilidade está "insatisfatória". Pelo ponto de visto técnico e também dos usuários o ponto de ônibus é avaliado como "satisfatório" por estar adjacente à praça, em funcionamento e em bom estado. Quanto aos estacionamentos pequenos, foi avaliado como "satisfatório" pelos usuários e "insatisfatório" pelo ponto de vista técnico, pois foi possível observar que os usuários da praça não podem usar seu estacionamento interno nos finais de semana por servir de garagem para os veículos da prefeitura, assim eles utilizam os estacionamentos das vias laterais do terreno.

Quanto à acessibilidade à pessoa com dificuldade de locomoção $(\mathrm{PcD})$, foi avaliada como "insatisfatória", devido às dificuldades de inclusão e acessos dos espaços. No que diz respeito à praça, percebese que devido ao fato dela ser plana, oferece boas condições de uso e largura dos passeios (Figura 7), porém, existem obstáculos (barreiras físicas) que dificultam o percurso nos passeios, além de não haver piso tátil e sinalizações. A pavimentação da praça, em hexagonal de concreto, foi avaliada como "insatisfatória", devido à falta de manutenção e deslocamento das peças, o que dificulta a locomoção e pode ocasionar acidentes.

O acesso ao edifício da prefeitura (Figura 8) acontece por uma pequena rampa na porta principal e por alguns degraus ao lado. No edifício alugado pela prefeitura não existe acesso para $\mathrm{PcD}$, pois existem apenas escadas de entrada. Na câmara municipal (Figura 9), o acesso principal acontece por uma escada e a rampa se localiza nos fundos, com difícil localização e em situações precárias. 


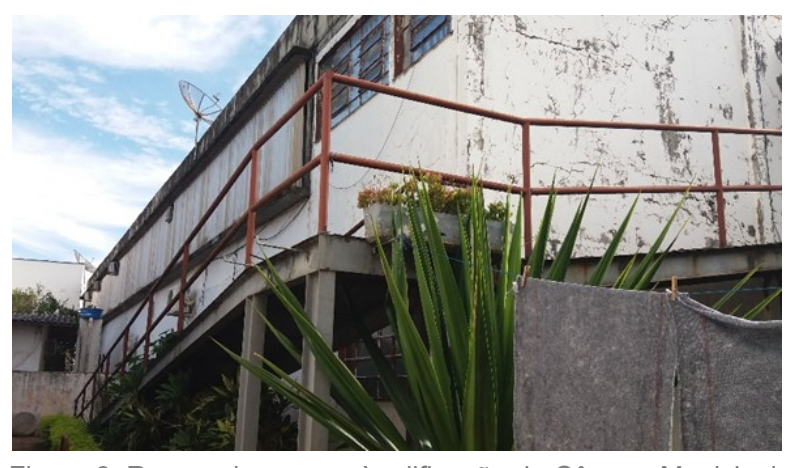

Figura 9. Rampa de acesso à edificação da Câmara Municipal de Coronel Vivida - PR. Fonte: Acervo da(s) Autor(as)

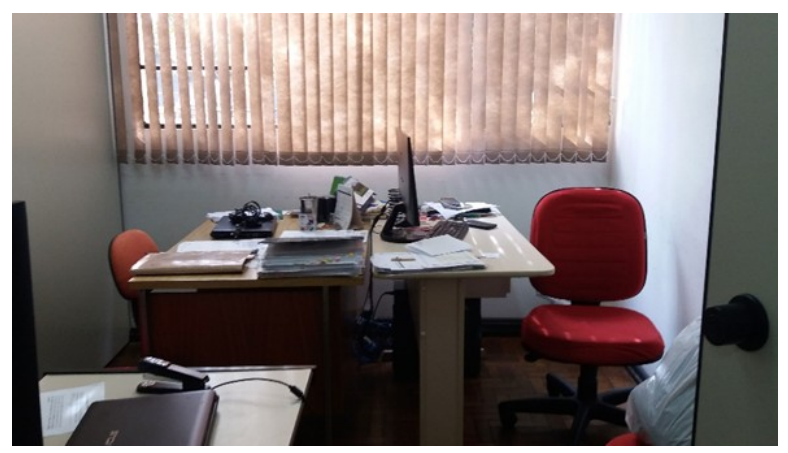

Figura 10. Tipologia dos ambientes de trabalho da Prefeitura Municipal de Coronel Vivida- PR. Fonte: Acervo da(s) Autor(as).

usjt • arq.urb • número 28 | maio-agosto de 2020
Quanto ao acesso à percepção e à vivência da qualidade arquitetônica do ambiente construído, a arquitetura do espaço acaba por não estimular a interação e as experiências sensoriais entre as pessoas, devido, principalmente, aos espaços enclausurados e pequenos para as atividades que exercem (Figura 10). As condições espaciais dos ambientes não satisfazem as necessidades dos usuários, pois não garantem a diversidade de usos e o direito à mobilidade.

\section{Identidade}

Os parâmetros de identidade classificam-se de forma diversificada na avaliação geral. Quanto à edificação principal, com proeminência por possuir a atividade mais importante, neste caso a edificação da prefeitura, foi avaliada como "satisfatória", pois a própria praça apresenta um caminho principal e mais largo que induz o acesso a ela.

Os parâmetros de espaço externo positivo e eventos comunitários foram avaliados como "neutros". Quanto ao espaço externo positivo não apresenta uma geometria clara, em que a delimitação favoreça a identificação do espaço. E, quanto ao critério de eventos comunitários, sabe-se que o espaço da praça é usado para festividades natalinas e alguns outros momentos em público, porém, é possível observar que o espaço não foi planejado visando a esses fins. Além disso, a arte pública é inexiste no local.
Todos os demais itens foram avaliados como "insatisfatórios". No atributo edificação como complexo os edifícios não apresentam programas que manifestem seus fatos sociais próprios. Assim como, quanto ao reconhecimento visual e significado, não se tem distinção de determinada edificação para outra pelo seu próprio significado. Quanto à arquitetura convidativa, os usuários afirmam não ser, pois ela restringe quanto ao atributo de acessibilidade e sua forma não deixa perceber o que representa.

Quanto ao critério de diversidade de usos, principalmente na praça o espaço não oferece mais usos além do playground para as crianças. Como sugestão, os usuários pediram por espaços terceirizados que sirvam cafés, lanches, sorvetes, entre outros, e que ao mesmo tempo preservem o local limpo.

\section{Legibilidade}

A avaliação dos parâmetros da legibilidade também foi diversificada. Apenas o critério de família de entradas foi avaliado como "satisfatório", devido à orientação das entradas para um mesmo local, neste caso, a praça. Os níveis legíveis de circulação, assim como o critério de caminhos, foram avaliados como "neutros", devido à conexão entre eles, pois organizar o espaço de modo que o usuário chegue a determinado ponto passando por níveis hierárquicos de importância e circule de forma habitual, ocasional ou potencial pelos caminhos não funciona na 
ausência de atributos de acessibilidade e estrutura, como exemplo.

Dessa mesma forma, os limites e setores foram avaliados como "insatisfatórios" em função das barreiras físicas e sonoras citadas no atributo de acessibilidade e estrutura. Além disso, existem poucas e pequenas aberturas voltadas para o espaço externo (praça) e isso acaba impondo limites visuais, sem permeabilidade visual e transparência entre os espaços. Os setores não apresentam características comuns que os tornem de fácil identificação e compreensão, o que atrapalha na orientação espacial.

Por fim, os parâmetros de pontos nodais e marcos foram avaliados como "inexistentes". Não foram observados pontos estratégicos, de concentração ou conexão, com significado funcional, nem pontos de referência perceptíveis que contribuíssem para a orientação no espaço.

\section{Conclusão}

Por meio deste trabalho é possível compreender a importância do espaço público, que favorece as manifestações de vida e a identidade de uma nação. A praça enquanto espaço público deve ser aberta, acessível e proporcionar encontros sociais e lazer. Quando ela está junto a uma arquitetura cívica, torna o local com maior representatividade so- cial dentro da cidade. Uma arquitetura como espaço democrático de livre circulação de ideias, de comunicação pública e política, sem causar opressão pela monumentalidade de seus edifícios.

Neste contexto, a humanização ressalta a importância do ser humano e da relação entre ambiente e comportamento do usuário. A integração entre o meio social e o espaço democrático acontece nessa medida. Quanto mais convidativa a forma, com mais presença de elementos naturais, estrutura, acessibilidade, identidade e legibilidade, mais inclusão e reconhecimento do espaço, no processo de criação de uma imagem mental gerada através do significado.

Com base nos parâmetros identificados, pode-se observar que a grande maioria dos usuários se sente insatisfeito com os parâmetros avaliados, tanto com a praça, quanto com os edifícios administrativos. Sendo assim, é necessário um planejamento que proporcione espaço ao público, no ambiente que administra e conduz a cidade. Nos espaços públicos, todos têm direitos, deveres e valores a serem respeitados, e podem vir a melhorar as condições urbanas, (re)descobrindo a cidade e (re)conhecendo o centro.

Deste modo, por meio da análise desses parâmetros de humanização para espaços públicos, foi possível levantar a situação atual dos espaços pú- 
blicos e administrativos de Coronel Vivida, Paraná, e perceber a necessidade de um novo projeto arquitetônico, urbanístico e paisagístico, a fim de valorizar a importância do centro urbano administrativo integrado à comunidade. Além disso, contribuir no processo de projeto, uma vez que os parâmetros podem ser aplicados em grande parte das cidades brasileiras, por meio da humanização do espaço, através da relação ambiente/comportamento, como forma de inclusão e representatividade social.

\section{Referências}

ALEX, Sun. Projeto da praça: convívio e exclusão no espaço público. 2. ed. São Paulo: Senac São Paulo, 2011.

ALEXANDER, Christopher et al. Uma linguagem de Padrões: A Pattern Language. Porto Alegre: Bookman, 2013.

ALMEIDA, Rachel de Castro. Paisagem urbana e espaço púbico: um estudo de duas praças de Belo Horizonte. Dissertação - Mestrado em Ciências Sociais na Pontifícia Universidade Católica de Minas Gerais. Belo Horizonte. 2001.

BARROS, Raquel Regina Martini Paula. Habitação coletiva: a inclusão de conceitos humanizadores no processo de projeto. 2008. 200f. Tese (Doutorado em Engenharia Civil, área de concentração Arquitetura e Construção) - Faculdade de Engenharia Civil, Arquitetura e Urbanismo, Universidade Estadual de Campinas, Campinas, 2008.

BENEDET, Michelle Souza; BENEDET, Juliane Souza; SILVA, Raiane Zapelini da. Produção do Espaço Público: uma avaliação sob o ponto de vista do usuário. In: CONGRESSO INTERNACIONAL DE ESPAÇOS PÚBLICOS, 1., 2015, Porto Alegre. Anais... Porto Alegre, 2015. Disponível em: 
$<$ http://docplayer.com.br/22571820-Producao-doespaco-publico-uma-avaliacao-sob-o-ponto-devista-do-usuario.html> . Acesso em: 10 mar. 2019.

BERNARDI, Núbia et al. O desenho universal no processo de projeto. In: KOWALTOWSKI, Doris Catharine Cornelie Knatz et al. (orgs.). O Processo de Projeto em Arquitetura: da Teoria à Tecnologia. São Paulo: Oficina de textos, 2011. p. 222-244.

BRANDÃO, Pedro. A identificação dos lugares e a sua representação coletiva: bases de orientação para concepção, qualificação e gestão do espaço público. Série Política de Cidades - 3. Centro de Sistemas Urbanos e Regionais (CESUR), Departamento de Engenharia Civil do Instituto Superior Técnico, Universidade Técnica de Lisboa, 2008.

CALDEIRA, Júnia Marques. A praça Brasileira: trajetória de um espaço urbano - origem e modernidade. Tese de Doutorado em História - Instituto de Filosofia e Ciências Humanas na Universidade Estadual de Campinas. [S.I.]. 2007.

ECKER, Vivian Dall'Igna; VAZ, Nelson Popini. Atributos espaciais para a qualificação de praças públicas urbanas. EURO ELECS 2015. Guimarães, Portugal, jul., 2015.
JACOBS, Jane. Morte e Vida de Grandes Cidades. São Paulo: Martins Fontes, 2007.

GEHL, Jan. Cidades para Pessoas. Tradução Anita Di Marco 2. ed. São Paulo: Perspectiva, 2013.

GRAVE, Luís et al. Carta Municipal do Espaço Público: Caracterização da rede dos espaços exteriores de vivência colectiva. Câmara Municipal de Odivelas. Odivelas, p. 1-49. 2011.

GOETTEMS, Renata Franceschet; BUENO, Ayrton Portilho. Mapeamento e análise dos espaços de praça da cidade de Joinville - SC. Revista Eletrônica de Arquitetura e Urbanismo. Universidade São Judas Tadeu, São Paulo, n. 22, p. 93-109, mai./ago. 2018. Disponível em: <https://www.usjt.br/arq.urb/ numero-22/6-renata-fraceshet.pdf>. Acesso em: 10 out. 2019.

HERTZBERGER, Herman. Lições de Arquitetura. São Paulo: Martins Fontes, 2015.

INSTITUTO BRASILEIRO DE GEOGRAFIA E ESTATÍSTICA - IBGE. Censo demográfico 2010. Rio de Janeiro: IBGE, 2010. Disponível em: https://censo2010.ibge.gov.br. 
LAMAS, José Manuel Ressano Garcia. Morfologia urbana e desenho da cidade. 1993. Lisboa: Fundação Calouste Gulbenkian e Junta Nacional de Investigação Científica e Tecnológica, s/d.

LYNCH, Kevin. A imagem da cidade. São Paulo: Martins Fontes, 2011.

MASCARÓ, Juan Luis. Infraestrutura da paisagem. Porto Alegre: Masquatro, 2008.

NÓBREGA, Maria de Lourdes Carneiro da Cunha; TRINDADE, Isabella Leite. Em busca do bom lugar. Revista Eletrônica de Arquitetura e Urbanismo. Universidade São Judas Tadeu, São Paulo, n. 25, p. 62-76, mai./ago. 2019. Disponível em: <https:// www.usjt.br/arq.urb/numero-25/4-marialourdes.pdf>. Acesso em: 09 out. 2019.

OLIVEIRA, Lucimara Albieri de; MASCARÓ, Juan José. Análise da qualidade de vida urbana sob a ótica dos espaços públicos de lazer. Ambiente Construído. Porto Alegre, v. 7, n. 2, p. 59-69, abr./ jun. 2007.

PEREIRA, Raquel Machado Marques. Três poderes: A Arquitetura Cívica Paulista, 1950-1970. 2012. 230f. Dissertação (Mestrado em Arquitetura e Urbanismo) - Universidade Presbiteriana Mackenzie, São Paulo, 2012.
QUEIROGA, Eugênio Fernandes. Sistemas de espaços livres e esfera pública em metrópoles brasileiras. Resgate. São Paulo, vol. XIX, n. 21, p. 2535, jan./jun. 2011.

RAMOS, Suzany Rangel; RAMOS, Larissa Leticia Andara; LYRA, Ana Paula Rabello. Espaço público e vitalidade: Parque linear como instrumento de reconciliação em área residual da infraestrutura viária. Revista Eletrônica de Arquitetura e Urbanismo. Universidade São Judas Tadeu, São Paulo, n. 24, p. 126-145, jan./abr. 2019. Disponível em: <https:// www.usjt.br/arq.urb/numero-24/7-susan.pdf>. Acesso em: 09 out. 2019.

RHEINGANTZ, Paulo Afonso et al. Observando a qualidade do lugar - Procedimentos para a avaliação pós-ocupação. Rio de Janeiro: Coleção Proarq/FAU/UFRJ, 2009.

ROGERS, Richard. Cidades para um pequeno planeta. Versão portuguesa de Anita Regina Di Marco. Barcelona: Editorial Gustavo Gili, 2001.

SANTIAGO, Paola Caiuby; MARCHESANO, Tiago. Guia do Espaço Público. 2. ed. São Paulo: Conexão Cultural, 2016. 
SITTE, Camilo. A construção das cidades segundo seus princípios artísticos. Tradução Ricardo Ferreira Henrique. 1992. São Paulo: Ática.

FENELON, Déa Ribeiro. Cultura e História Social: Historiografia e Pesquisa. In: Projeto História 10. Revista do Programa de Estudos de PósGraduados em História e do Departamento de História da PUC-SP. São Paulo: EDUC, 1993, p. 73-90 